\title{
ORDEM BANCÁRIA COMO MEIO DE PAGAMENTO EM INSTITUIÇÕES PÚBLICAS FEDERAIS
}

\author{
Alexandre Pioner de Lima ${ }^{1}$ \\ Miguelina Troisi Bonfrisco ${ }^{2}$
}

\section{Resumo}

A movimentação da Conta Única do Tesouro Nacional é efetuada por intermédio das Unidades Gestoras - UGs, integrantes do SIAFI - Sistema Integrado de Administração Financeira, sob a forma de acesso on-line, utilizando como Agente Financeiro o Banco do Brasil e o Sistema de Pagamentos Brasileiro - SPB para transferências diretas às instituições financeiras. Um dos documentos utilizados pela Conta Única é a ORDEM BANCÁRIA - OB, utilizada para pagamento de obrigações da UG e demais movimentações financeiras. $O$ objetivo deste artigo é discorrer sobre esta modalidade de pagamento utilizada pelo Governo Federal, analisando as diferentes apresentações de Ordens Bancárias e sua eficiência operacional. Avaliar a eficiência da modalidade de pagamento de Ordem Bancária - OB para permitir o controle imediato de gastos sobre as disponibilidades financeiras do Governo Federal. Quanto a sua natureza, a pesquisa é básica, objetivando produzir conhecimentos úteis para o avanço das ciências. Quanto à abordagem do problema, a pesquisa é qualitativa, não requerendo o uso de métodos e técnicas estatísticas. Quanto ao ponto de vista de seus objetivos, a pesquisa é exploratória, com a utilização de pesquisas bibliográficas. Quanto ao ponto de vista dos procedimentos técnicos, a pesquisa é bibliográfica, utilizando material já publicado, constituindo-se basicamente de livros e artigos periódicos, com informações disponibilizadas na internet. Como conclusão, temos que a Ordem Bancária apresenta-se como uma ferramenta que propicia a desburocratização dos meios de pagamento, pois é executada em um ambiente simples e amigável, eliminando a emissão de uma grande quantidade de papéis.

Palavras-chave: Ordem Bancária. OB. Conta Única. Pagamentos.

\footnotetext{
${ }^{1}$ Mestre em Administração. PUC-Rio - Administrador do Serviço de Orçamento do Hospital de Clínicas de Porto Alegre. aplima@hcpa.edu.br

${ }^{2}$ Pós-Graduação em Administração Financeira. UNIASSELVI - Chefe do Serviço de Finanças do Hospital de Clínicas de Porto Alegre. mbonfrisco@hcpa.edu.br
} 


\title{
BANK ORDER AS A MEANS OF PAYMENT IN FEDERAL PUBLIC INSTITUTIONS
}

\begin{abstract}
The movement of the National Treasury Single Account is made through the Management Units - UGs, members of the Integrated Financial Administration System (SIAFI), in the form of online access, using Banco do Brasil and the Payments System as the Financial Agent. Brasileiro - SPB for direct transfers to financial institutions. One of the documents used by the Single Account is the BANK ORDER - BO, used to pay UG obligations and other financial transactions. The purpose of this article is to discuss about this type of payment used by the Federal Government, analyzing the different presentations of Banking Orders and their operational efficiency. To evaluate the efficiency of the Bank Order - OB payment method to allow the immediate control of expenses on the Federal Government financial resources. As for its nature, the research is basic, aiming to produce useful knowledge for the advancement of the sciences. Regarding the approach to the problem, the research is qualitative, not requiring the use of statistical methods and techniques. As for the point of view of its objectives, the research is exploratory, with the use of bibliographical research. Regarding the point of view of technical procedures, the research is bibliographic, using material already published, consisting basically of books and periodical articles, with information available on the Internet. In conclusion, we have that the Banking Order is presented as a tool that facilitates the bureaucracy of means of payment, as it is executed in a simple and friendly environment, eliminating the issuance of a large amount of paper.
\end{abstract}

Keywords: Bank Order. BO. Single Account. Payments.

\section{INTRODUÇÃO}

O pagamento é a terceira e última etapa da execução da despesa, precedida pelo empenho e liquidação. No governo federal o pagamento é realizado por meio do SIAFI, com a emissão de Ordem Bancária - OB, documento que possui várias espécies e características próprias, variando de acordo com o tipo de pagamento a ser realizado.

\footnotetext{
A Ordem Bancária é o meio de pagamento utilizado pelos órgãos públicos federais, denominados Unidades Gestoras, para repasse de recursos relativos a programas do governo federal e também para pagamento a seus funcionários e fornecedores, mediante crédito em conta corrente na rede bancária ou pagamento em espécie no Banco (Manual SIAFI, 2019, p.1).
} 
É um documento que deve ter como favorecido o credor do empenho. Este pagamento normalmente é efetuado por meio de crédito em conta bancária do favorecido uma vez que a Ordem Bancária especifica o domicílio bancário do credor a ser creditado pelo agente financeiro do Tesouro Nacional, ou seja, o Banco do Brasil. Se houver importância paga a maior ou indevidamente, sua reposição aos órgãos públicos deverá ocorrer dentro do próprio exercício, mediante crédito à conta bancária da unidade gestora que efetuou o pagamento.

O artigo científico abordará o detalhamento de emissão da Ordem Bancária, como também as várias modalidades existentes. Ao mesmo tempo, destacará a eficiência deste tipo de meio de pagamento.

A pesquisa constará de coletas bibliográficas encontradas na internet, de onde partirá a fundamentação teórica-empírica que norteia o trabalho. A fundamentação dos objetivos será feita através de pesquisa no Portal da Transparência do Governo Federal. Através da análise destes dois elementos serão feitas as interpretações dos dados e conclusões da pesquisa.

\section{ORDEM BANCÁRIA - OB}

O processamento dos pagamentos por meio de OB é operacionalizado a partir do envio da ordem bancária para o Banco do Brasil ou para Banco Central. Isso não significa que o favorecido terá conta bancária no $\mathrm{BB}$ ou Bacen, mas apenas que os recursos transitarão por essas entidades, as quais serão responsáveis pelo encaminhamento dos valores a cada instituição financeira em que o credor possua domicílio bancário (BARROZO; MACHADO, 2014).

A ordem bancária $(\mathrm{OB})$ deve ser precedida da inclusão e realização do documento hábil no SIAFIWeb, com a emissão da ordem de pagamento (OP). Assim, após a realização do documento hábil será gerada a OP que, após assinada pelo gestor financeiro e ordenador de despesas, gerará automaticamente a Ordem Bancária correspondente (MANUAL SIAFI, 2019, p.1).

As ordens bancárias que transitam pelo BB são enviadas de 30 em 30 minutos ao Banco entre $8 \mathrm{~h} 10 \mathrm{~min}$ e $16 \mathrm{~h} 40 \mathrm{~min}$. No último arquivo são encaminhadas as OBs geradas até 16h20min. Caso as assinaturas ocorram após o horário limite (16h20min) para envio no último arquivo, a respectiva OB somente será gerada e enviada no dia útil seguinte. As ordens bancárias com trânsito pelo Banco Central serão geradas e enviadas no mesmo dia somente se forem assinadas até às 18h10min. Caso as assinaturas ocorram após esse horário, a respectiva OB somente será gerada e enviada no dia útil seguinte (MINISTÉRIO DA FAZENDA, 2019, p.1).

Não há prazo para assinatura da OP pelo gestor financeiro e o ordenador de despesa (respeitando-se os horários de funcionamento do SIAFI). Assim, uma vez que ocorra a 
liquidação da despesa e a realização do documento hábil correspondente, bem como a geração da OP, a falta de assinatura do ordenador de despesa ou do gestor financeiro não ocasionará o cancelamento da ordem de pagamento tampouco da ordem bancária, vez que a OB somente será gerada com ambas as assinaturas.

\subsection{Tipos de Ordens Bancárias - OB}

Conforme Silva (2006), as Ordens bancárias que transitam pelo Banco do Brasil são:

- Ordem Bancária de Crédito - OBC

OB para pagamento diretamente na conta bancária do beneficiário, que pode ser pessoa física ou jurídica com domicílio bancário com validação. Deve ser previamente cadastrado no Siafi, através da função ATUDOMCRED. É utilizada para pagamento de diárias ao servidor. Não possui lista de credores, ou seja, cada OB só pode ter um único favorecido. $\mathrm{O}$ crédito na conta do favorecido será no primeiro dia útil seguinte à geração da OB no caso do BB.

- Ordem Bancária de Pagamento - OBP

OB para pagamentos a pessoa física que não possui conta corrente. Cada OB só pode ter um único favorecido, não permitindo a vinculação de lista de credores. Não deve ser utilizada para pagamento de pessoa jurídica, ou para favorecido que possuir conta bancária. Caso não for sacada no prazo de sete dias corridos da geração da Ordem Bancária, ocorrerá cancelamento automático pelo banco.

- Ordem Bancária Banco - OBB

OB destinada para pagamento de várias pessoas de uma única vez, através de lista de credores. Também é utilizada para pagar faturas cujo pagamento não possa ser realizado por meio de OB Fatura.

- Ordem Bancária Fatura - OBD

A OBD é utilizada para pagamento de faturas (convênios ou títulos) com código de barras. Mesmo que seja uma só fatura, só pode ser emitida com lista de fatura,. Primeiro é preciso identificar qual espécie de fatura (se título ou se convênio). Se o código de barras 
começar com o número 8 será sempre convênio. Se constar da fatura a expressão "pagável em qualquer banco", trata-se de título.

- Ordem Bancária de Câmbio - OBK

Utilizada para pagamento de operações de contratação de câmbio, diárias em moeda estrangeira, e pagamentos em moeda estrangeira, tendo como destinatário o Banco do Brasil. Utilizada quando o servidor viaja para o exterior e precisa portar moeda estrangeira, para pagar suas despesas em outro país. A OBK é emitida em reais, mas os recursos são sacados no Banco do Brasil na moeda combinada com o BB.

As Ordens bancárias que transitam pelo Banco do Central são:

- Ordem Bancária Reserva - OBR

Para pagamento com envio dos recursos diretamente na conta reserva do banco favorecido, no Banco Central. Só pode ser emitida pelas UGs autorizadas pela COFIN/STN. É necessário combinar com o banco favorecido que o envio dos recursos será realizado por meio desse tipo de OB.

- Ordem Bancária Folha - OBF

Para pagamento de despesa com pessoal e também pagamento de empréstimo com consignação em folha de pagamento em que o favorecido seja um banco. Não pode ser usada para pagamento de pessoa jurídica. Caso o favorecido seja um CNPJ, este deve ser um banco. Para este tipo de OB, é necessário realizar convênio como banco favorecido para que sejam transmitidas a ele as informações sobre os favorecidos, como o domicílio bancário. Utiliza-se um documento hábil FL para geração desta OB.

- Ordem Bancária Judicial - OBJ

Utilizada para processos judiciais nos quais a decisão judicial ainda não foi concluída. Também utilizada para pagamento de depósito recursal do FGTS (Caixa) e para depósito em conta vinculada, no caso de proteção e gestão de riscos na execução de contratos de prestação de serviços com utilização de somente mão-de-obra. No caso de pagamentos de depósitos judiciais, exige-se o Identificador de Depósito - ID Depósito. Esse ID é um código com 18 
dígitos, criado no site do banco (ou de alguns tribunais), após o preenchimento de informações sobre o processo judicial.

- Ordem Bancária Pagamento de Processo Judicial - OBH

Utilizada para pagamento de sentenças judiciais transitadas em julgado, relativas a precatório, requisições de pequeno valor (RPV) ou ações que tramitam nos Juizados Especiais. Emitida somente pelas UGs autorizadas. A criação de lista de processos judiciais é obrigatória. Pode-se anexar relação de beneficiários.

O novo processo de geração de ordem bancária foi implantado em $1^{\circ}$ de janeiro de 2019. É constituído das seguintes etapas:

1. Inclusão do documento hábil no SIAFIWeb;

2. Realização do compromisso na transação GERCOMP (Gerenciar Compromisso) que resultará no documento Ordem de Pagamento - OP e nova Nota de Sistema NS.

3. Assinatura da OP, na transação GEROP (Gerenciar Operação), pelo gestor financeiro e ordenador de despesa;

4. Confirmação da assinatura do ordenador de despesa;

5. Pesquisa dos documentos pendentes de assinatura do gestor financeiro;

6. Assinatura do gestor financeiro;

7. Confirmação da assinatura do gestor financeiro;

8. Detalhamento da OP após as duas assinaturas;

9. Geração automática da ordem bancária.

Após este processo, podem ser consultadas no SIAFI a relação de Ordens Bancárias OB, como também todos os tributos que incidem sobre cada nota fiscal de fornecimento, seja de material ou serviço, como o Documento de Arrecadação de Receitas Federais - DARF, a Guia da Previdência Social - GPS, o Documento de Receitas de Estados e/ou Municípios DAR, e a Guia de Recolhimento do FGTS e de Informações da Previdência Social - GFIP.

Os recursos vêm da Conta Única do Governo Federal, que é o mecanismo que permite a movimentação on-line de recursos financeiros dos Órgãos e Entidades ligadas ao SIAFI em conta unificada. Esta unificação, além de garantir a manutenção da autonomia e individualização, permite o controle imediato dos gastos sobre suas disponibilidades financeiras. Diariamente, pode-se realizar a conciliação das contas bancárias (MANUAL SIAFI, 2019, p.1).

Neste processo, temos os seguintes conceitos básicos (MANUAL SIAFI, 2019): 
1. Documento de Origem: é o recibo, nota fiscal ou qualquer outro documento (papel), emitido pela unidade ou pelo fornecedor, que será cadastrado no sistema.

2. Documento Hábil - DH: é o documento cadastrado no sistema que gera compromissos de pagamento ou de recebimento, podendo ser de previsão (Nota de Empenho - NE), Contrato, Proposta de Programação Financeira etc.) ou de Realização (Nota Fiscal - NF), Recibo, Folha de Pagamento, Programação Financeira Aprovada, etc.).

3. Documento de Referência: é um documento hábil cujos dados servirão de base para um outro documento hábil, que, ao ser cadastrado, baixará os compromissos do primeiro no valor correspondente; ex.: A Nota de Empenho - NE é um documento de referência para a Nota Fiscal de Pagamento.

4. Situação: é o indicador que determina o que será contabilizado quando da liquidação e realização ou cancelamento do documento hábil, bem como seu relacionamento com o documento de referência (exigência, tipo, equivalência de valor etc.); é a situação que indica os eventos a serem aplicados.

5. Dedução/Encargos: corresponde às retenções de impostos e contribuições, bem como de descontos, cujos valores serão deduzidos do valor do documento, ou encargos decorrentes da emissão de documentos ficais.

6. UG Pagadora/Recebedora: é a unidade gestora responsável pelo pagamento/recebimento dos compromissos gerados pelo documento hábil de realização, inclusive os decorrentes de retenções/encargos.

7. Credor/Devedor: identifica a entidade credora do compromisso, se documento de pagamento ou retenção/encargos, ou devedora, se documento de recebimento;

8. Compromissos: são os valores a pagar ou a receber gerados a partir do cadastramento de um documento hábil, podendo ser também de previsão (anterior à liquidação) ou de realização (já liquidado).

\section{CONSIDERAÇÕES FINAIS}

Foi observado que existem várias modalidades de Ordens Bancárias executadas no SIAFI. Estas englobam todas as possibilidades de pagamentos existem em nosso sistema financeiro. Isso permite fazer uma integração com sistemas de orçamento público, empenhos, 
liquidações, dívida pública, contratações de serviços, compra de bens, convênios públicos e outros. Todas essas informações estão disponíveis para consulta pública através do Portal da Transparência do Governo Federal.

Através do Portal da Transparência é possível averiguar tudo o que foi pago por cada Unidade Gestora e o que foi recebido por cada fornecedor de bens e serviços. Além disso, verifica-se o que foi gasto e o que foi orçamento em cada âmbito do Governo Federal.

A Ordem Bancária apresenta-se como uma ferramenta que propicia a desburocratização dos meios de pagamento, pois é executada em um ambiente simples e amigável, eliminando a emissão de uma grande quantidade de papéis. Todos os documentos podem ser consultados a qualquer momento.

A partir de 1992, parou-se de emitir cheques bancários e começou-se a realizar os pagamentos integralmente através de Ordens Bancárias - OB. Com isso, as Unidades Gestoras obtiveram um ganho de eficiência nos processos de Contas a Pagar e Receber CPR. Todas as operações de emissão de OB, DARF, DAR, GPS e GFIP estão integradas com a Contabilidade Pública do Governo Federal. Isso permite a contabilização no mesmo momento em que as operações são efetuadas.

Com a vinculação das Ordens Bancárias - OB e os documentos de tributação (DARF, DAR, GPS e GFIP), o governo garante a retenção dos tributos, diminuindo a possibilidade de sonegação fiscal das empresas que fornecem ao Serviço Público.

Em suma, foi verificado que esta modalidade de pagamento é eficiente, pela agilidade de operação e pelo grau de transparência em que se apresenta. 


\section{REFERÊNCIAS}

BARROZO, Maiara. MACHADO, Genivieve. Material para capacitação interna do FIPLAN - Módulo Nota de Ordem Bancária - NOB. Salvador, 2014.

BRASIL. Instrução Normativa STN No 4, de 31 de julho de 1998, publicado no Diário Oficial da União em 03 de agosto de 1998.

CASTRO. Patrícia Barbosa de. Os documentos do SIAFI como fonte de informações gerenciais. Monografia apresentada ao Programa de Pós-Graduação em Administração (PPGA) da Faculdade de Economia, Administração, Contabilidade e Ciência da Informação e Documentação (FACE), da Universidade de Brasília. Orientador: Gilvan da Silva Dantas. Brasília, 2009.

ECO, Umberto. Como se faz uma tese. Perspectiva : São Paulo, 1996.

HÜHNE, Leda Miranda. Metodologia científica. Agir : Rio de Janeiro, 1995.

MINISTÉRIO DA FAZENDA. Manual SIAFI. Assunto 020305: Conta Única do Tesouro Nacional. Disponível em http://manualsiafi.tesouro.fazenda.gov.br/020000/020300/020305. Acesso em 06 de maio de 2019.

SEVERINO, Antonio Joaquim. Metodologia do trabalho científico. Cortez : São Paulo, 1996.

SILVA. Louise Caroline. Modalidades de Ordem Bancária. III Semana de Administração Orçamentária, Financeira \& de Contratações Públicas - Ministério da Fazenda - MF. Brasília, 2006.

TESOURO NACIONAL. Manual de Ordem Bancária. Disponível em http://www.tesouro.fazenda.gov.br/manual-ordem-bancaria. Acesso em 06 de maio de 2019.

UNIVERSIDADE FEDERAL DO PARANÁ. Normas para apresentação de trabalhos Vol. 7. UFPR : Curitiba, 1995. 